\title{
Study of Harmony in Hisaishi Joe's Animated Music
}

\author{
Wen Tian \\ Shandong University Of Arts (Shandong China 250014)
}

Keywords: Hisaishi Joe; Animated music; Harmonic analysis

\begin{abstract}
As one of the most influential artistic masters of modern composers in Asia, Hisaishi Jean's musical works can be said to be the world-class musical works of today, and he is a milestone in the soundtrack of movie and television. In order to better analyze the characteristics and artistic functions of Hisaishi Joe's animated music, this study first introduces the life and creative experience of Hisaishi Joe, and then explains the artistic function of harmony in Hisaishi Joe's animated music, and then introduces the sounding art of Hisaishi Joe's animated music. Finally, the aforesaid contents are combined with the revelation of Hisaishi Joe's animated muics to Chinese animation film music, and also hopes to create conditions for the development of Chinese animation film industry.

Hisaishi Joe has a wide range of creative fields. His major not only involves piano and symphony, but also has profound knowledge of electronic music and advertising music. When mentioning his works, we first think of the classic repertoire of the animated film work created by Master Hayao Miyazaki, and Hisaishi Joe portrayed the character's emotions into every audience's heart when he scored the music. This is why he is good at capturing musical notes, and it is also one of the rare success factors in Hayao Miyazaki's films. If you want to understand the harmony of Hisaishi Joe, you must first understand his life and creative trajectory.
\end{abstract}

\section{Part One Hisaishi Joe's Life and Creation}

In the seventies and eighties of the last century, Japanese animation gained worldwide attention with its unique artistic style and thought-provoking humanistic connotations, which also made Japan formally establish its position as a world's animation power. In the process of the rapid development of Japan' s animation and cultural industry, Hisaishi Joe, who enjoys the "Music of Asia's music score" , has made tremendous contributions. Hisaishi Joe was born in 1950, formerly known as Fujisawa-ku, and his ancestral home was in Nagano City, Nagano Prefecture, Japan. He first wrote many early works as a solo artist. Later he was inspired by his friend's introduction and personal inspiration to name himself, and gradually developed into a world-renowned music master.Hisaishi Joe began to study the violin at the age of four with world-renowned music educator Suzuki Shinichi and successfully entered the National University of Music. As one of the most influential musicians in Asia, Hisaishi Joe created many outstanding works during his more than 30 years of creative career. Among the most influential ones are the "Winds" created in collaboration with Hayao Miyazaki. Later, they successively created the music of the "Princess Phantom" and "Thousand Spirited Away" and other excellent works, which not only pushed Miyazaki to become the world's top animation production masters, but also decided the status of his own Asian music score.

\section{Part Two Artistic Function of Harmony in Hisaishi Joe's Animated Music}

Promoting the Development of the Plot. Hisaishi Joe climbed to the top in the field of animated music, not only because of his in-depth research on harmony, but also benefited from his accomplishments in the independent field of animated music. Objectively speaking, animated film and television music has an important influence on the plot development. As a highly fictional artistic expression, in order for the audience to fully integrate into a world that is irrelevant to the real world or even to the contrary in the viewing process, it is also very important to select a 
suitable music score. It is the use of different harmony art to promote the development of the plot. This is reflected in the animation such as Spirited Away.

Creating a Time and Space Cultural Background. In the creative process, the music and the picture book belong to an independent parallel relationship, but as a viewer, it is indeed to integrate the two together to watch. As a composer, in addition to enhancing the combination of picture and chords as a whole, it is also necessary to pay attention to the "description" feature of musical chords. For example, in "Spirited Away", when Xiao Qian enters an abandoned house with his parents, in order to match the unique space-time culture background in the plot, Hisaishi Joe selected a very different chord type, which made the audience feel very nervous. It is also a strong point of its chords.

Exquisite Emotional Catharsis. The sense of the screen is what we often refer to in the production of animation. When dealing with some "exquisite" emotional catharsis, the effect of the picture is often not as direct as music. However, generally speaking, we rarely allow the audience to "feel the same feelings" through music alone. Therefore, the animated music of Hisaishi Joe and the picture of Hayao Miyazaki have been skillfully combined to achieve a combination of exquisiteness and ruggedness, thereby enhancing the emotional characteristics which lets the audience unconsciously into the animation of the emotional world.

\section{Part Three Art of Harmony in Hisaishi Joe's Animated Music}

\section{Selection of Chord Materials}

Hisaishi Joe has deep piano music production skills coupled with the early learning of the violin and other mainstream stringed instruments, so the choice of chord materials has very wide range, and the characteristics are even more extensive. In addition to the traditional three-degree superposition chords, it also makes full use of the more complex three-degree superposition chords. At the peak of its business, it adds the most modern features of non-triple overlapping chords to various works. Although the material selection of its chords is very extensive, the location and effect of the application are very subtle, and this is where the world is most stunned. Because the choice of chord materials is quite diversified and very sophisticated, Hisaishi Joe's strong expression of harmony is very strong. It can easily control various thematic images, so as to be closely linked to the theme of the animated film, and can even be made to leak.

\section{Harmony Forming}

In the application of the harmonic technique of Hisaishi Joe's animated music, the chord is paid great attention to. In general, a single and isolated chord can not form a music, it must need to have certain rhythm can be composed to melody, and this is the biggest difference between the composer and the ordinary people, and some composers often do not know how to weave the chord, which reduces the effect of chord. Hisaishi Joe has the feature animation and traditional function, simultaneously has also been integrated into the large vocabulary characteristics of sound, so they can break the characteristics and objective functional harmony vocabulary, shading and thinking so as to control the whole harmony, which is also not easy stereotypes. In market research, we find that the music of Hisaishi Joe's audience is very extensive, and it can not only make many nationalities, ideology, culture degree under the conditions of the groups fascinated by its music or even a full concert, and many people listen to music but do not understand music, which is the charm of harmony.

\section{Terminate}

Terminate is the end part of the music cadence in harmony, and it is the harmony thinking point of distinction, but also one of the most significant sign of different music and skills, and we often terminate the composer's type as an important symbol of the artistic features. From the form of composition, Hisaishi Joe's music and harmony are characterized by the not the same of the beginning and the end and the strong flexibility. Especially in some recent animation works, Hisaishi Joe is very good at using cadence harmony to emphasize its artistic value and creativity, and thus gain a more successful and sound effects, and even the industry called "Mark of Hisaishi", 
and it is enough to see their works in the identification of high cadence.

\section{Harmony Texture}

In the animated music, the proper harmonic texture not only enhances the artistic image of the work, but also complements the advancement of material and harmony, and ultimately realizes the expression of emotions and emotions of the musical composition, thereby they are embodying stronger artistic rendering power. In his musical works, Hisaishi Joe pays great attention to the rendition of harmonic textures. Its greatest characteristics can be summed up as "simple" and "clear". Among them, the simplicity is mainly reflected in the less disturbance of the vocal part among the harmonic textures. By highlighting the characteristics of the melody part in the works by minimizing the interference, the music score is no longer the exclusive domain of people in the professional field, and it becomes a piece of music art works of "complicity and popularity" . From the perspective of the processing of chords and sounds, Hisaishi Joe lets the sound of each fabric reflect the penetration of the music, and at the same time promotes the development of the entire film story. For example, in "Red Fighter", the theme music has high recognition, and it made a good response.

\section{Part Four the Revelation of Harmony in Hisaishi Joe's Animated Music for Chinese Animation Film Music}

\section{Aesthetic Value of Harmony in Hisaishi Joe's Animated Music}

Hisaishi Joe's animated music is world-famous, and the key lies in the expressiveness of harmony aesthetic values. Looking at all of Hisaishi Joe's animated soundtracks, he reveals the characteristics of "fine". This depends not only on his good soundtrack foundation and ability to control, but also on his dedication to music for many years. No matter from the perspective of the artistic value and commercial value of Hisaishi Joe's music cultivation, he is the first person to deserve the present day's animation film score.

\section{The Revelation of Hisaishi Joe's Animated Music to Chinese Film Music}

Hisaishi Joe's animated music and harmony art are ingenious and quintessential, which not only has the power to move people, but also has the characteristics of delicate flowing. As the creator of animation and soundtracks in our country, we must maintain a heart of learning and development, and learn the persistent enthusiasm and spirit of Hisaishi Joe. We must realize that there is an objective relationship between animation developed countries such as China and Japan, but also should continue to strengthen their own creative level, and establish a stronger than the animation of the country's confidence, so that we can ultimately achieve cultural rejuvenation and national prosperity, and continue to make greater contributions to China's film and music industry.

\section{Conclusion}

To sum up, Hisaishi Joe's position in the field of animated film and music is unshakable, and the special film music and sound techniques he created have had a profound influence on the modern animation film and even the entire field of film and television music. Many scholars at home and abroad currently have extensive research on Hisaishi Joe's music harmony. One of the most impressive things for the author is his definition of "concise but not simple". As a milestone in the process of the nationalization of world music, we must study the special aesthetic value shown by Hisaishi Joe in the animated music, and thus strengthen the creative level of the Chinese animated film music, and then provide technical support for the rise of the level of harmonization techniques to contribute to the overall healthy development of China's cultural industry. 


\section{Reference}

[1] Johnson. An analysis of Hisaishi Joe's animated film music and sound art[J].The Sound of the Yellow River,2017(18):101.

[2] Shen Lin. A study of Hisaishi Joe's animated film music[D].Hunan University of Technology,2015.

[3] Maomao Bai.A study on the harmony of Hisaishi Joe's animated film music[J].The Sound of the Yellow River,2014(21):79.

[4] Long Wang. The expression of harmony and music emotion in Hisaishi Joe's Piano Works[J].Qilu Realm of Arts,2014(03):20-24.

[5] Long Wang. The study of Hisaishi Joe's animated film music and sound art[D].Shandong Normal University,2014. 